Football, sport and the development of young people's life skills

Edward Cope ${ }^{\mathrm{a}}$, Richard Bailey ${ }^{\mathrm{b}}$, Daniel Parnell ${ }^{\mathrm{c}}$ and Adam Nicholls ${ }^{\mathrm{a}}$.

${ }^{\text {a }}$ Department of Sport, Health and Exercise Science, University of Hull, Hull, UK

${ }^{\mathrm{b}}$ Council of Sport Science and Physical Education, Berlin, Germany

${ }^{\mathrm{c}}$ Business School, Manchester Metropolitan University, Manchester, UK

Emails: Ed.Cope@hull.ac.uk; baileyrichard1@me.com; d.parnel1@mmu.ac.uk;

A.Nicholls@hull.ac.uk 


\title{
Football, Sport and the development of young people's life skills
}

\author{
Edward Cope ${ }^{a^{*}}$, Richard Bailey ${ }^{b}$, Daniel Parnell ${ }^{\mathfrak{c}}$ and Adam \\ Nicholls ${ }^{\mathrm{a}}$.
}

\begin{abstract}
The development of life skills has been associated with participation in sport, football and other physical activities. A factor in enabling this ambition to be realized is the actions and behaviors of sports coaches. Drawing on the concept of positive youth development through sport, the first part of this paper considers the types of environments coaches need to create in order for players to develop life skills. The second part of this paper discusses formal coach education and it's role in developing coaches' knowledge of life skills development. The third and final section of this paper offers an alternative explanation of how people's exposure to certain social contexts results in the development of life skills. A review of literature in these areas reveals that the role sport and football has played in players' development of life skills is unclear and in need of future research attention.
\end{abstract}

Key words: Life skills, football, sport, coach, education

\section{Introduction}

The benefits on people's physical health through taking part in regular sport and other activities have received a significant amount of research interest, and are now well understood. However, it has also been acknowledged that sport and in particularly football is able to contribute to people's health beyond just the physical (Bingham et al. 2014; Curran et al. 2014; Parnell et al. 2015; Parnell and Richardson 2014) For example, 'explicit' theories such as the Human Capital Model (HCM) draw on available scientific evidence to make claims that the outcomes associated with sport and physical activities are not limited to the physical, but rather extend into the social, psychological, and intellectual domains of learning (Bailey et al. 2012, 2013). A further claimed non-physical outcome of participation in sport and physical activity is the development of a person's life skills. Given the global consumption on football it is important to consider its role in promoting and fostering life skills. This paper will refer to football and its contribution toward developing people's life skills, however

\footnotetext{
${ }^{*}$ Corresponding author. Email: Ed.Cope@hull.ac.uk
} 
given the paucity of research in this area, research in sport more generally will be drawn upon.

Recent decades have witnessed a growth of interest among policy makers and practitioners in the promotion of skills seen as integral to preparing young people and adults in dealing with everyday challenges and risks, and enable productive participation in society (Hodge and Danish, 1999; Miller and Kerr 2002). Often called 'life skills', these skills have gained currency in the fields of health, education and social policy. Sport has also been increasingly recognized as a means by which people are able to develop skills that allow them to positively contribute toward society. This is perhaps hardly surprising given that the inherent nature of sport requires people to demonstrate such things as perseverance when attempting to learn new skills, or social and cognitive skills as people are required to work independently and interdependently to solve problems and make decisions.

Intimation of the power of sport to extend beyond the physical to improve players' lives more generally continues to be made as if they are truisms. Former British Prime Minister Tony Blair said that "Sport is the best health policy, education policy, anti-crime policy and anti-drugs policy", while the Mayor of London, Boris Johnson, proposed team games as a cure for gang violence, and the former Education Secretary, Michael Gove, identified football, and other competitive team games as the 'better' games for 'building character' (Erdozain 2012). Similar claims can be found in the enthusiast endorsements of sport from politicians around the world. That is, the often taken for granted assumption that taking part in sport leads to positive outcomes being developed. Of course, it is difficult to know whether politicians genuinely consider sport to have such power, or it is in their political interests or agendas to promote it as such.

These assertions are not limited to politicians, however, and have received support in the field of academia. Indeed, Petitpas et al. (2005) claimed that sport is able to provide the basis for youth to learn about themselves and acquire skills that will prove useful later in life. This view is shared by others who posited that sport has the capacity to challenge and motivate people in ways not found in other life pursuits, such as schooling or work (Hansen, Larson, and Dworkin 2003) Indeed, Jones and Lavallee (2009) found that adolescent athletes considered interpersonal skills (e.g., social skills, respect, and leadership) and personal skills (e.g., discipline, self-reliance, and goal setting) as important skills necessary to succeed in life. 
In complex and contested areas, it is useful to be clear about the meanings attributed to the words used. As is clear even from the brief commentary above, skills promoted by participation in sport are as ambitious as they are ill defined. As the World Health Organisation (WHO) stated, "Skills that can be said to be life skills are innumerable, and the nature and definition of life skills are likely to differ across cultures and settings" (p. 1). Yet, the WHO claimed there were a core set of identifiable skills that are at the heart of skills-based initiatives for the promotion of the health and well-being of children and adolescents, including: decision making; problem solving; creative thinking; critical thinking; effective communication; interpersonal relationship skills; self-awareness; empathy; coping with emotions; and coping with stress. UNICEF offered a somewhat more restricted definition of life skills in terms of "psychosocial abilities for adaptive and positive behavior that enable individuals to deal effectively with the demands and challenges of everyday life" (unpaged). This organization also identified three broad categories of skills: "cognitive skills for analyzing and using information, personal skills for developing personal agency and managing oneself, and inter-personal skills for communicating and interacting effectively with others" (ibid.). This definition offers a relatively clear scope for life skills, and reflects the use of the concept employed in this article.

Before progressing to the discussion of the focus of this article, namely life skill development through sport and football, it might be useful to reflect for a moment more on the notion of 'skills' per se, as it will usefully set the scene for the subsequent argument, as well as highlight why sport is so often linked to life skills. Bailey and Pickard (2010) proposed four hypotheses about skill learning. The first hypothesis stated that skills were learned. That is to say that skills are acquired, and that without this process of acquisition, there would be no skills. Thus learning is a necessary feature of skill (Moe 2004). Secondly, skill "can be defined only in terms of success, of achievement, of a goal" (Guthrie 1952 p. 136) In other words, skills are actions with some outcome in mind, rather than merely techniques or actions. The distinction between skill and mere technique (or action) is a vitally important one for the discussion that follows. Simply put, skills need to be used and applied with some success; they are not academic or theoretical constructs. Third, the development of skill requires practice, and this practice is most effective when it takes place in meaningful settings. Finally, skills have a history in the sense that they develop in some way over time. As they have somehow survived well-enough to turn up for an 
educational or sporting lesson, it is probably reasonable to assume that all of the students in a group have developed a complement of life skills already. Skill learning does not begin with ignorance; it builds on existing expertise. With these reflections in mind, it will be useful to consider in more detail how sports like football might (or might not) offer worthwhile contexts for the development of life skills.

A number of factors appear to determine whether sport is able to contribute toward a person attaining and building upon existing life skills. Coakley (2011) drew on research evidence to offer a list of factors that need to be in place for certain outcomes to be achieved, which include the orientations and actions of coaches, and the norms and culture associated with particular sports or sport experiences. We have stated these two factors here as they form the basis of the discussion in this article, as we consider it to be far beyond the scope to discuss each factor (for the full list of factors see Coakley 2011 pp. 209-210).

The purpose of this article is threefold. First, we discuss the type of learning environment coaches need to create to best enable players to develop life skills. Coaches are key agents in ensuring people have enjoyable and worthwhile sporting experiences (Smoll and Smith 1989), therefore it is important to examine how they can enhance these experiences and create an optimal learning environment for the development of life skills. We discuss this specifically in relation to the context of youth sport. Again, it is not possible within the scope of this article to consider how coaches should structure the learning environment across all coaching contexts. Accordingly, we made the decision to focus on youth sport, as this is the context in which most coaching takes place (Sports Coach UK 2011). Second, we review formal coach education provision and its contribution toward developing coaches' knowledge and understanding of how to develop their players' life skills. Third, we offer a broader examination of how life skills are formed. Therefore, we will draw on evidence more generally in sport to support our discussions in order to better develop an understanding of how football has the potential to contribute towards life skills development.

\section{Structuring the learning environment}

Regardless of sport, a factor that could determine the development of players' life skills is how the sports environment is structured (Miller and Kerr 2002). Coaches have a significant role to play in ensuring the sporting development of young people 
through the way they structure the coaching environment (Baker and Horton 2004; Côté et al. 2009) and the behaviours they employ (Cumming, Smoll, and Smith, 2006. While not the only parameter needed for life skill development, coaches' actions are a determining factor toward the fostering of players' life skills (Gould et al. 2002; Gould et al. 2007)

An approach that impacts upon the development of life skills in youth is positive youth development (PYD) (Lerner et al. 2005). The premise of PYD is that all youth have some form of resource or inherent capability from which they can lead happy and successful lives. This approach is in opposition to viewing youth as having a knowledge and skill deficit, to one where they have assets or strengths to be built upon. For example, if a player has some level of social skills, a PYD approach develops these skills further, in order to provide that player with a positive mindset of achievement rather than failure.

As this theory became an established means to understand how to effectively develop people's skills, it was considered that sport had the means by which to contribute (Fraser-Thomas, Côté, and Deakin 2005; Vella, Oades, and Crowe 2013. For example, a PYD through sport approach has been suggested to contribute towards the development of fair play, leadership, goal setting and teamwork (Larson 2000). A PYD through sport approach aims to develop outcomes that move beyond the mastery of physical or technical skills. PYD through sport has been associated with the development of a diverse range of sport-specific and non-sport specific skills (Vella et al. 2013), which include but are not limited to the 5 Cs of competence, confidence, caring/compassion, connection and character (Lerner et al. 2005).

To achieve the development of a broad range of skills, it has been suggested that coaches need to create a mastery-oriented environment, where emphasis is placed on self-improvement, rather than a process-oriented, or coach-centred environment that prioritizes winning and short-term gains (Holt and Kneely 2011) Cope, Bailey, and Pearce (2013) discussed how a mastery-oriented environment is aligned with young people's reasons for participating in sport. When these are applied, coaches place priority on the interests of their players and motivating them to accept the wider goals of the group at the expense of the short-term, self-interests of individuals (Avolio and Bass 2002) Findings from other studies claim positive changes in attitudes toward coaches, sport, and the self have been observed in young people where coaches were more reinforcing, encouraging, and autonomy supportive than 
coaches who were critical of performance, emphasized winning, and attempted to control athlete behaviour (Bartolomew, Ntoumanis, and Thorgerson-Ntoumani 2009; Bennie and Connor 2012; Conroy and Coatsworth 2007; Smith and Smoll 1990; Smoll, Smith, Barnett, and Everett 1993. However, Cowan et al. (2012) suggested that not all young people will be suitably prepared to deal with responsibilities of leadership and decision making. Instead, they argued for more situation-specific coaching behaviours that align with what young people need and want at the various stages of their development. However, it has been reported that where coaches have created more process-oriented learning environments the consequences have been lack of enjoyment and dropout from sport (Fraser-Thomas et al. 2005; Wall and Côté 2007)

The extent to which coaches create a learning environment that fosters the development of life skills has been questioned. Research conducted in developmental contexts within the United Kingdom (UK) revealed that football coaches predominantly use authoritarian styles of coaching (Cushion and Jones 2006; Potrac, Jones and Cushion 2007; Partington and Cushion 2013). This is manifested in practice through coaches' high use of prescriptive behaviours such as management, instruction and feedback, and low usage of questioning and silence. However, authoritarian coaching extends beyond the behaviours coaches employ to the way practice times are scheduled to the ways players are expected to behave (Denison 2007). Cushion and Jones (2006) suggest that coaches adopt this approach to exercise control and discipline over their players, in order to preserve their status within a sub-culture of academy football. This results in players being passive and docile recipients of coaching, rather than active learners who feel valued (Cushion and Jones 2014; Denison 2007). In light of this, it is unlikely that this type of environment will enable players the opportunity to develop life skills. However, in studies where expert coaches (often characterized as those who have more than 10 years coaching experience, and have a successful winning record) have been the focus, it has been found these coaches do not exercise such authoritarianism. For example, Vallee and Bloom (2005) study with five expert Canadian coaches established that these coaches attempted to enable their athletes to learn, grow and reach their potential by showing care and a genuine interest in their welfare and lives, both in and outside of sport. It has been documented in other studies that expert coaches place a high priority on establishing personal growth with their athletes (Bloom and Salmela 2000; Saury and 
Durand 1998; Voight and Carroll 2006). Thus, for these coaches they appear to adopt a mastery-oriented environment where they appreciate their athletes as people who have a life outside of sport.

\section{The contribution of coach education in the development of life skills}

Coaches' ability to adopt a PYD approach, or something similar, has been conditioned by their knowledge and experiences (Camire', Trudel, and Fomeris 2014; Cushion, Armour, and Jones 2003). Cushion et al. (2003) wrote that coaches' socialisation experiences influence their beliefs, which then act as a filter for the acquisition of new knowledge. So, coaches' learning experiences both within and outside the context of sport will govern the beliefs coaches hold, which manifests through coaching practice. It is common in coaching for coaches to reproduce in their practice what they experienced as players, observers, or novice coaches (Cushion and Jones 2006; Cushion and Jones 2014). Often this is a predominant focus on the technical aspects of the sport, with coaches failing to appreciate how they can impact on the wider development of their players (Tinning 1988), and have little consideration for the wider outcomes that players could develop. Even when coaches think they are doing something beyond that of a technician, Cushion (2013) claims they are likely not, as coaches' theories-in-use rarely align with their theories-in-action. Studies that have observed and interviewed coaches regarding their practice have found there to be a dissonance between what they thought they did, with what they actually did Partington and Cushion 2013; Partington, Cushion, and Harvey 2014). Given that traditional rhetoric is the prevailing discourse many coaches will not adopt more mastery-oriented approaches that better enable life skill development.

If coaches are to move closer toward creating an environment optimal for life skill development, there needs to be a deliberate shift in how they think about their coaching role. It has been suggested that a crucial factor to achieving this is the development of competent and knowledgeable coaches (Camire' et al. 2014). While coaches learn to coach via a number of different sources (e.g. observing and interacting with other coaches, reading and viewing coaching related material, learning from coaching experience) (Nelson, Cushion, and Potrac 2006; Stoszkowski and Collins 2015; Werthner and Trudel 2006) in places such as the UK, North America, and Canada, formal coach education in the form of national qualifications is normally the mandatory requirement for most coaching roles. As such, it would 
appear national qualifications have much potential in being the place for coaches to learn about how to develop their players' life skills.

Coaches who have not received training or educational provision in how to develop life skills are unable to explicitly state how they provided their players opportunities to develop these (Gould et al. 2007; McCallister, Blinde, and Weiss 2000). For example, volunteer youth baseball and softball coaches in McCallister et al's. (2000) study, who had not completed any formal coach education, were unable to articulate how they taught life skills in their actual practices, even though they acknowledged the importance of developing these in young people. On the other hand, some evidence suggests that coaches who have experienced some form of training or education specific to the development of life skills are more likely to create environments that enable these to flourish (Camire' et al. 2014; Gould et al. 2007; Vella et al. 2013). For example, American football coaches in Gould et al's. (2007) study who had attended specialized training in life skills spoke about strategies they tried to employ with their players, which included treating players respectfully, using various motivational techniques, and team building. It is important to make it clear that the training these coaches and players received were specific to learning about life skills, and not part of standard coach education programmes.

In fact, where standard, large-scale coach education programmes have been the focus of study; research in a UK context has consistently found these have failed to impact on the learning and practices of coaches, and specifically in football (Cushion et al. 2003; Stodter and Cushion 2014). One of the main criticisms leveled at coach education has traditionally been the prioritization of the acquisition and assessment of content knowledge (e.g. knowing what different activities could be delivered to players) (Daniel and Bergmann-Drewe 1998; Tinning 1988. Historically, coaching has tended to view coaches' knowledge of subject matter as being the most important for them to carry out their role effectively (Bergmann- Drewe 2000), as has been evidenced by the focus and content of coach education curricula being on how to develop the technical aspects of players' performance (Nelson and Cushion 2006). Yet, Cushion et al. (2003) state that 'if imaginative, dynamic, and thoughtful coaches are to be developed, then coach education must be about more than developing content knowledge' (p.216). So, sport needs to provide opportunities for players to develop more than their physical or technical skills, to encouraging the development of ethics, citizenship and lifelong skills. Evidence has already been drawn on which 
indicates that coaches who have not received life skills training will be less likely to know how to develop these skills than coaches who have received training in this area.

Educational programmes have also been developed with the purpose of developing peoples' life skills. Two such examples are the Going for the Goal (GOAL) programme and the Sports United to Promote Education and Recreation (SUPER) programme. These programmes were developed in North America and exclusively for under-served youth with the aims of developing their sense of control and confidence to enable them to become better citizens and contribute more positively toward society (Danish and Nellen 1997). These programmes used the medium of sport to teach adolescents about the importance of developing skills that can be transferred into other areas of their lives. Specially trained high school students delivered the GOAL programme to middle school (aged 11-14) or junior school students (aged 7-11), and for the SUPER programme specially trained higher education (aged 18-21) students delivered to younger adolescents. Prior to this, experts in the field of life skill development taught the school students responsible for delivering these programmes. Students who had been part of these programmes reported increases in their knowledge about life skills, and a perceived increase in competence of attaining goals that they had set (Danish and Nellen 1997). Other studies (Brunelle et al. 2007; Goudas and Giannoudis 2008) that investigated the impact of the SUPER programme have also claimed that students who received this programme showed an enhanced knowledge of life skills and an increase in self-belief compared with students who did receive this programme. While it is acknowledged that these programmes have been taught in specific contexts with a specific group of people, there would appear to be the scope and need to develop programmes that specifically attend to life skill development.

Recent attempts by a number of sports groups in the UK have been made to re-validate existing coach education programmes in order for them to better meet the needs of coaches, and subsequently, players. This came as a consequence of sports coach UK's (scUK) (scUK is that national agency for coaching, which recruits, retains and develop coaches) requests to develop coaches' knowledge that more realistically met the demands of coaching in specific contexts (Nash and Sproule 2009; North 2009). For example, the English Football Association (EFA) created youth modules, which are coaching programmes specifically designed for coaches 
working with children. The focus of these modules has moved away from developing coaches' content knowledge toward placing a greater emphasis on increasing coaches' pedagogical knowledge and interpersonal knowledge, which was needed if coaches were to develop players' life skills more effectively (Côté and Gilbert 2009.) Unfortunately, initial evidence suggests these programmes do not result in changes to coaching practice (Stodter and Cushion 2014), even though coaches may perceive that they do. In fact, a weakness with the available evidence is that there has been a reliance on perceptions of change, rather than measured change. All of the studies cited in this paper have drawn only upon how coaches, or students believe the life skills programme they completed has impacted their ability to develop these within their players. Given work done in coaching, which has found coaches inability in being able to accurately identity how they coach (Harvey, Cushion, Cope and Muir 2014; Partington and Cushion 2013) the current evidence base is weak and requires further research attention.

The prevailing discourse of education, with this extending to coaching, permits that the person served with educating is assumed to be the knowledge bearer (Freire 1998) This has been termed the transmission method whereby coach educators pass on their knowledge to coaches (Parton and Bailey 2008). The problem is that the learner is forced to be passive in the learning process, and individual needs are ignored. If coaches are to construct learning environments that allow players to develop life skills, what seems to be required to bring about changes in practice is a wider suite of educational provision, which includes in-house education that enables coaches to discuss issues specific to their role (Partington et al. 2015). Where this is not the case, there is limited evidence to suggest that coach education programmes are impacting on coaches' applied knowledge. Miller and Kerr (2002) offer some thoughts as to how educational programmes can better prepare coaches to develop their player's life skills. They claim that education programmes need to develop coaches' understanding of how to nurture and empower their players, and in doing so, break down the imbalance in power, which has been reported exists between coach and player in some youth football contexts (Cushion and Jones 2006). So, coaches need educating about how to move from a transmitter of knowledge toward a facilitator, who is able to support players with their learning, as well as make them feel an important and integral part of the learning process. Mattick and Knight (2007) found that learning that was self-directed, problem-based, contextualized and project- 
based led to high-quality learning. Furthermore, it has been argued that when content is relevant and meaningful motivation is likely to be higher, which has a positive impact on learning and development (Nicol and MacFarlane-Dick 2006).

Research concerning the impact that formal coach education has had on coaches' development of knowledge is unclear and mixed. The general consensus is that coach education programmes have had limited impact. However, where there has been a specific focus on developing coaches' knowledge in a specific area, such as life skills, there is some research that suggests coach education programmes to have had some impact. Unfortunately, these claims remain weak given that reports are based on coaches' perceptions of impact, rather than actual impact measured by observing coaches use of knowledge in practice.

\section{Understanding how life skills are formed}

Players, like coaches, enter education programmes with varying levels of existing knowledge and experiences from which to draw on. It is these experiences that act as the filtering system that conditions the development of new knowledge (Cushion et al. 2003). The likelihood that an educational programme contributes to a player's development of life skills is significantly increased when the player sees relevance and meaning in the content being delivered and the knowledge and skills required to achieving success (Bailey 2000; Bransford, Brown and Cocking 2000). For example, if players already consider they have high levels of knowledge and skill regarding psychological aspects of performance they may not find educational programmes in this area overly useful, or worse still as harmful or irrelevant to their sporting career. Moreover, players must also see value in the way the educational programme is delivered (Bailey 2014).

There has been a diverse body of work in education that shows that if the method of delivery does not align with students' beliefs about learning, or what they feel they need to know then the educational programme is less likely to lead to learning taking place, or at least not the intended learning (Cano 1995; Schommer 1990; Schommer and Walker 1995). The beliefs people hold are shaped by their previous life experiences, and shapes future life experiences (Bourdieu 1990). This has implications for life skill development as the learning environments and opportunities people have experienced will impact the extent to which they already possess life skills, and how they are able to develop them. An example of where this 
is the case can be found in Jones and Lavallee's (2009) study in tennis. Their study explored how a female tennis player perceived her life skills had developed. This player believed it was the nature of tennis that had led her to learn specific life skills, which would have not have been developed otherwise. For example, this player spoke about having developed the mentality of not giving up easily, instead persevering when things may not be going her way. She attributed the development of this skill to being placed in situations in tennis, which required skills like this being developed. Interestingly, the player in this study did not consider that she was taught life skills by her coach or parents, although she did acknowledge that the environment these had created did enable her life skills to flourish.

In a study that examined how life skills had been learnt within the context of a youth soccer team, Holt et al. (2008) found that players perceived they developed these skills because of the culture of the high-school, rather than learnt through being coached football. For example, signs were located around the schools' sporting facilities that reminded players of the values and ethos of the school. This is what Turnnidge, Côté and Hancock (2014) term the implicit transfer of life skills from one learning domain to another. This was also found to be the case in Jones and Lavellee's (2009) study, although it was considered that certain life skills transfer between certain learning domains better than others. Explicit transfer of life skills is when these are deliberately taught in one context and then applied in another. It would seem that evidence to support the transfer of life skills is again limited beyond people's perceptions. So, while pockets of evidence exist such as those discussed here, there is not a substantive body on which to draw.

\section{Conclusion}

The purpose of this paper was to discuss the role sport played in the development of player's life skills. This paper specifically aimed to address the type of learning environments coaches needed to create to enable player's life skills to flourish, and how coaches had been prepared by formal coach education to construct such environments. The final element of this paper was to offer a brief discussion of how people's life skills had formed. In summary of the research, how players best develop life skills is inconclusive. There have been some suggestions that the actions and behaviours of coaches is a fundamental factor toward players developing life skills. 
Indeed, Danish (2002) claim coaches need to deliberately plan their coaching interventions if players' life skills are to be developed, with there being further suggestions that simply playing sport will not lead to positive outcomes, such as life skills development (Fraser-Thomas et al. 2005; Gould et al. 2007; Larson 2006) Instead, for life skill development to be achieved what is needed is careful consideration from coaches as to how they structure the learning environment, interact, and form relationships with their players (Gould et al. 2007). A masteryoriented environment has been reported as most appropriate in providing a context by which player's are able to develop a wide range of skills, which include life skills.

Research findings provide some evidence that coaches who have been specially trained in life skills development are better placed than those coaches who have little or no training in this area. However, in general, there is limited evidence to suggest formal coach education has any actual impact on coaches' practices, even though there are a number of studies that have reported how coaches perceive these programmes to have impacted. As well as coaches receiving formal training in life skills development, there have also been programmes that have directly looked to develop young peoples' life skills. Two such programmes (GOAL and SUPER) have been discussed in this study, with findings indicating that these had perceived impact, but again, there has been a failure in recognising whether there was an actual impact.

There have been claims that simply being involved in sport does not automatically lead to the development of life skills (Danish and Nellen 1997). However, some studies have suggested that the culture of particular sports or learning contexts can result in life skills being developed, without the need for these to be taught. This evidence is perhaps particular to certain contexts as some researchers (Coalter 2007) do not consider there to be a robust enough evidence base to make claims that sport does lead to positive developmental gains, but instead, participation can just as easily lead to the development of negative outcomes (Coakley 2011; Makkai et al. 2003), such as mental health issues and drug abuse.

The landscape at present is unclear of how sport contributes toward players' life skill development. Pockets of evidence exist that suggests it does if coaches act and behave in certain ways, or there is a culture that player's associate with that they consider contributes toward their development of life skills. Given the role of football 
as a global game in terms of participation across youth and adult populations, it is apparent that more empirical work is needed that considers how life skills are developed through this sport (and others), and transferred into other life domains.

\section{References}

Avolio, B. J., and B. M. Bass. 2002. "Manual for the multifactor leadership questionnaire (Form 5X)." Redwood City, CA: Mindgarden.

Bailey, Richard. 2000. Education in the open society: Karl Popper and schooling. Aldershot: Ashgate.

Bailey, Richard. 2014. Teaching values and citizenship across the curriculum: educating children for the world. London: Routledge.

Bailey, Richard, and Angela Pickard. 2010. "Body learning: examining the processes of skill learning in dance." Sport, Education and Society 15 (3): 367-382.

Bailey, Richard, Charles Hillman, Shawn Arent, and Albert Petitpas. 2012. "Physical Activity as an Investment in Personal and Social Change: The Human Capital Model." Journal of Physical Activity and Health 9 (8): 1053-1055.

Bailey, Richard, Charles Hillman, Shawn Arent, and Albert Petitpas. 2013. "Physical activity: an underestimated investment in human capital." Journal of Physical Activity and Health 10 (3): 289-308.

Cope, Edward, Bailey, Richard, and Gemma Pearce. 2013. "Why do children take part in, and remain involved in sport? A literature review and discussion of implications for sports coaches." International Journal of Coaching Science 7 (1): 5675.

Baker, Joseph, and Sean Horton. 2004. "A review of primary and secondary influences on sport expertise." High Ability Studies 15 (2): 211-228. 
Bartholomew, Kimberley J., Nikos Ntoumanis, and Cecilie Th $\oslash$ gersen-Ntoumani. 2009. "A review of controlling motivational strategies from a self-determination theory perspective: Implications for sports coaches." International Review of Sport and Exercise Psychology 2 (2): 215-233.

Bennie, Andrew, and Donna O'Connor. 2012. "Perceptions and strategies of effective coaching leadership: A qualitative investigation of professional coaches and players." International Journal of Sport and Health Science 10: 82-89.

Biggs, John. 2003. "Aligning teaching for constructing learning". Higher Education Academy.

Bingham, D. D., D. Parnell, K. Curran, R. Jones, and D. Richardson. 2014. "Fit Fans: Perspectives of a Practitioner and Understanding Participant Health Needs within a Health Promotion Programme for Older Men Delivered within an English Premier League Football Club.” Soccer and Society 15 (6): 883-901.

Bloom, G. A., and J. H. Salmela. 2000. "Personal characteristics of expert team sport coaches." Journal of Sport Pedagogy 6: 56-76.

Bose, Mihir. 2012. The spirit of the game: how sport made the modern world. Hachette UK.

Bourdieu, Pierre. "The logic of practice, trans. R. Nice." (1990).

Bransford, John D., Ann L. Brown, and Rodney R. Cocking. 2000. "How people learn." Washington DC: National Academy Press.

Brunelle, John, Steven J. Danish, and Tanya Forneris. 2007. "The impact of a sportbased life skill program on adolescent prosocial values." Applied developmental science 11 (1): 43-55. 
Camiré, Martin, Pierre Trudel, and Tanya Forneris. 2014. "Examining how model youth sport coaches learn to facilitate positive youth development." Physical Education and Sport Pedagogy 19 (1): 1-17.

Cano, Francisco. 2005. "Epistemological beliefs and approaches to learning: Their change through secondary school and their influence on academic performance." British Journal of Educational Psychology 75 (2): 203-221.

Coakley, Jay. 2011. "Youth Sports What Counts as "Positive Development?" Journal of sport \& social issues 35 (3): 306-324.

Coalter, Fred. 2007. A wider social role for sport: who's keeping the score? Routledge: London.

Conroy, David E., and J. Douglas Coatsworth. 2007. "Assessing autonomy-supportive coaching strategies in youth sport." Psychology of sport and exercise 8 (5): 671-684.

Côté, Jean, and Wade Gilbert. 2009. "An integrative definition of coaching effectiveness and expertise." International journal of sports science and coaching 4 (3): 307-323.

Coté, Jean, Sean Horton, Dany MacDonald, and Scott Wilkes. 2009. "The benefits of sampling sports during childhood." Physical \& Health Education Journal 74 (4) (2009):

Coubertin, P. de. 2000. "The trustees of the Olympic idea." Olympism: Selected writings: 587-589.

Cowan, Daryl T., Ian M. Taylor, Hayley E. McEwan, and Julien S. Baker. 2012. "Bridging the gap between self-determination theory and coaching soccer to disadvantaged youth." Journal of Applied Sport Psychology 24 (4): 361-374. 
Curran, K., D. Bingham, D. Richardson, and D. Parnell. 2014. "Ethnographic Engagement from within a Football in the Community Programme at an English Premier League Football Club.” Soccer and Society 15 (6): 934-950.

Cushion, Christopher J. 2013. "Applying game centered approaches in coaching: A critical analysis of the 'dilemmas of practice' impacting change." Sports Coaching Review 2 (1): 61-76.

Cushion, Christopher J., Kathy M. Armour, and Robyn L. Jones. 2003. "Coach education and continuing professional development: Experience and learning to coach." Quest 55 (3): 215-230.

Cushion, Christopher, and Robyn L. Jones. 2006. "Power, discourse, and symbolic violence in professional youth soccer: The case of Albion Football Club." Sociology of Sport Journal 23 (2): 142.

Cushion, Christopher J., and Robyn L. Jones. 2014. "A Bourdieusian analysis of cultural reproduction: Socialisation and the 'hidden curriculum'in professional football." Sport, Education and Society 19 (3): 276-298.

Danish, Steven J. 2002. "Teaching life skills through sport." Paradoxes of youth and sport: 49-60.

Danish, Steven J., and Valerie C. Nellen. 1997. "New roles for sport psychologists: Teaching life skills through sport to at-risk youth." Quest 49 (1): 100-113.

Denison, Jim. 2007. "Social theory for coaches: A Foucauldian reading of one athlete's poor performance." International journal of sports science and coaching 2 (4): 369-383.

Drewe, Sheryle Bergmann. 2000. "An examination of the relationship between coaching and teaching." Quest 52 (1): 79-88. 
Erdozain, Dominic. 2012. "Does Sport Build Character? A Progress Report on a Victorian Idea." Studies in Christian Ethics 25 (1): 35-48.

Fraser-Thomas, Jessica L., Jean Côté, and Janice Deakin. 2005. "Youth sport programs: An avenue to foster positive youth development." Physical Education \& Sport Pedagogy 10 (1): 19-40.

Friere, Paulo. 1998. "Pedagogy of freedom." Maryland: Rowman \& Littlefield.

Goudas, Marios, and Georgios Giannoudis. 2008. "A team-sports-based life-skills program in a physical education context." Learning and instruction 18 (6): 528-536.

Gould, D., K. Collins, L. Lauer, and Y. Chung. 2002. "Examining strategies outstanding high school football coaches use to develop life skills and character in their players: Final project report." University of North Carolina.

Gould, Daniel, Karen Collins, Larry Lauer, and Yongchul Chung. 2007. "Coaching life skills through football: A study of award winning high school coaches." Journal of applied sport psychology 19 (1): 16-37.

Guthrie, Edwin Ray. 1952. "The psychology of learning (rev)."

Harvey, Stephen, Christopher J. Cushion, Edward Cope, and Bob Muir. 2013. "A season long investigation into coaching behaviours as a function of practice state: the case of three collegiate coaches." Sports Coaching Review 2 (1): 13-32.

Hansen, David M., Reed W. Larson, and Jodi B. Dworkin. 2003. "What adolescents learn in organized youth activities: a survey of self-reported developmental experiences." Journal of Research on Adolescence 13 (1): 25-55.

Hodge, K., and S. Danish. 1999. "Promoting life skills for adolescent males through sport." Handbook of counseling boys and adolescent males: A practitioner's guide: 55-71. 
Holt, Nicholas L., and Kacey C. Neely. 2011. "Positive youth development through sport: A review." Revista iberoamericana de psicología del ejercicio y el deporte 6 (2): 299-316.

Holt, Nicholas L., Lisa N. Tink, James L. Mandigo, and Kenneth R. Fox. 2008. "Do youth learn life skills through their involvement in high school sport? A case study." Canadian Journal of Education/Revue canadienne de l'éducation: 281-304.

Jones, Martin I., and David Lavallee. 2009. "Exploring perceived life skills development and participation in sport." Qualitative research in sport and exercise 1(1): 36-50.

Larson, Reed W. 2000. "Toward a psychology of positive youth development." American psychologist 55 (1): 170.

Larson, Reed. 2006. "Positive youth development, willful adolescents, and mentoring." Journal of community psychology 34 (6): 677.

Lerner, Richard M., Jason B. Almerigi, Christina Theokas, and Jacqueline V. Lerner. 2005. "Positive youth development." Journal of early adolescence 25 (1): 10-16.

Makkai, Toni, Leesa Morris, Jo Sallybanks, and Katie Willis. 2003. Sport, physical activity and antisocial behaviour in youth. Australian Institute of Criminology.

Mattick, Karen, and Lynn Knight. 2007. "High-quality learning: harder to achieve than we think?." Medical Education 41 (7): 638-644.

McCallister, Sarah G., Elaine M. Blinde, and Windee M. Weiss. 2000. "Teaching values and implementing philosophies: Dilemmas of the youth sport coach." Physical Educator 57 (1): 35.

Miller, Patricia S., and Gretchen A. Kerr. 2002. "Conceptualizing excellence: Past, present, and future." Journal of Applied Sport Psychology 14 (3): 140-153. 
Moe, Vegard Fusche. 2004. "How to understand skill acquisition in sport." Bulletin of Science, Technology \& Society 24 (3): 213-224.

Nash, Christine, and John Sproule. 2009. "Career development of expert coaches." International Journal of Sports Science and Coaching 4 (1): 121-138.

Nelson, Lee J., and Christopher J. Cushion. 2006. "Reflection in coach education: The case of the national governing body coaching certificate." Sport Psychologist 20 (2) (2006): 174.

Nelson, Lee, Christopher Cushion, and Paul Potrac. 2006. "Formal, nonformal and informal coach learning: A holistic conceptualisation." International Journal of Sports Science and Coaching 1 (3): 247-259.

Nicol, David J., and Debra Macfarlane-Dick. 2006. "Formative assessment and selfregulated learning: A model and seven principles of good feedback practice." Studies in Higher Education 31 (2): 199-218.

North, Julian. 2009. "The coaching workforce 2009-2016." Leeds: Sports Coach UK.

Parnell, D., A. Pringle, S. Zwolinsky, J. McKenna, Z. Rutherford, D. Richardson, L. Trotter, M. Rigby, M.J. Hargreaves. 2015. 'Reaching Older People with Physical Activity Delivered in Football Clubs: The Reach, Adoption and Implementation Characteristics of the Extra Time Programme'. BMC Public Health 15. doi:

10.1186/s12889-015-1560-5. http://www.biomedcentral.com/1471-2458/15/220.

Parnell, D., and D. Richardson. 2014. "Introduction." Soccer and Society 15 (6): 823827.

Parnell, D., Stratton, G., Drust, B., and D. Richardson. 2013. "Football in the Community Schemes: Exploring the Effectiveness of an Intervention in Promoting Positive Healthful Behaviour Change." Soccer and Society 14(1): 25-51. 
Partington, Mark, and Christopher Cushion. 2013. "An investigation of the practice activities and coaching behaviors of professional top-level youth soccer coaches." Scandinavian Journal of Medicine \& Science in Sports 23 (3): 374-382.

Partington, Mark, Christopher Cushion, and Stephen Harvey. 2014. "An investigation of the effect of athletes' age on the coaching behaviours of professional top-level youth soccer coaches." Journal of Sports Sciences 32 (5): 403-414.

Partington, Mark, Christopher J. Cushion, Ed Cope, and Stephen Harvey. 2015. "The impact of video feedback on professional youth football coaches' reflection and practice behaviour: a longitudinal investigation of behaviour change." Reflective Practice 16 (5): 700-716.

Parton, Graham, and Richard Bailey. 2008. "Problem-based learning: a critical rationalist perspective." London Review of Education 6 (3): 281-292.

Petitpas, Albert J., Allen E. Cornelius, Judy L. Van Raalte, and Tiffany Jones. 2005. "A framework for planning youth sport programs that foster psychosocial development." The Sport Psychologist 19 (1): 63-80.

Potrac, Paul, Robyn Jones, and Christopher Cushion. 2007. "Understanding power and the coach's role in professional English soccer: A preliminary investigation of coach behaviour." Soccer and Society 8 (1): 33-49.

Saury, Jacques, and Marc Durand. 1998. "Practical knowledge in expert coaches: Onsite study of coaching in sailing." Research Quarterly for Exercise and Sport 69 (3): 254-266.

Schommer, Marlene. 1990. "Effects of beliefs about the nature of knowledge on comprehension." Journal of Educational Psychology 82 (3): 498.

Schommer, Marlene, and Kiersten Walker. 1995. "Are epistemological beliefs similar across domains?" Journal of Educational Psychology 87 (3): 424. 
Smith, Ronald E., and Frank L. Smoll. 1990. "Self-esteem and children's reactions to youth sport coaching behaviors: A field study of self-enhancement processes." Developmental Psychology 26 (6): 987.

Smoll, Frank L., and Ronald E. Smith. 1989. "Leadership Behaviors in Sport: A Theoretical Model and Research Paradigm1." Journal of Applied Social Psychology 19 (18): 1522-1551.

Smoll, Frank L., Ronald E. Smith, Nancy P. Barnett, and John J. Everett. 1993. "Enhancement of children's self-esteem through social support training for youth sport coaches." Journal of Applied Psychology 78 (4): 602.

Stodter, Anna, and Christopher J. Cushion. 2014. "Coaches' learning and education: a case study of cultures in conflict." Sports Coaching Review 3 (1): 63-79.

Stoszkowski, John, and Dave Collins. 2016. "Sources, topics and use of knowledge by coaches." Journal of Sports Sciences 34 (9): 794-802.

Tinning, Richard. 1988. "Student teaching and the pedagogy of necessity." Journal of Teaching in Physical Education 7: 82-89.

Turnnidge, Jennifer, Jean Côté, and David J. Hancock. 2014. "Positive Youth Development From Sport to Life: Explicit or Implicit Transfer?" Quest 66 (2): 203217.

Vallée, Chantal N., and Gordon A. Bloom. 2005. "Building a successful university program: Key and common elements of expert coaches." Journal of Applied Sport Psychology 17 (3): 179-196.

Vella, Stewart, Lindsay Oades, and Trevor Crowe. 2013. "A pilot test of transformational leadership training for sports coaches: impact on the developmental experiences of adolescent athletes." International Journal of Sports Science and Coaching 8 (3): 513-530. 
Voight, Mike, and Pete Carroll. 2006. "Applying sport psychology philosophies, principles, and practices onto the gridiron: An interview with USC football coach Pete Carroll." International Journal of Sports Science and Coaching 1 (4): 321-331.

UNICEF (2003) Definition of Terms: life skills.

http://www.unicef.org/lifeskills/index 7308.html (accessed 8/1/16).

UNICEF (2012) Global Evaluation of Life Skills Education Programme. New York: United Nations Children's Fund.

Wall, Michael, and Jean Côté. 2007. "Developmental activities that lead to dropout and investment in sport." Physical Education and Sport Pedagogy 12 (1): 77-87.

Werthner, Penny, and Pierre Trudel. 2006. "A new theoretical perspective for understanding how coaches learn to coach." Sport Psychologist 20 (2): 198.

World Health Organization (1997) Life Skills Education in Schools, WHO Programme on Mental Health. Geneva: WHO. 